\title{
Tourism and third sector organisations: synergies for responsible tourism development?
}

\author{
Turismo e terceiro sector: sinergias para o desenvolvimento turístico responsável?
}

Paula Guerreiro Martins

School of Management, Hospitality and Tourism, Universidade do Algarve, and CITUR, Portugal, pmartins@ualg.pt

Ana Maria Alves Ferreira

School of Social Sciences, University of Évora, Portugal, amferrei1951@gmail.com

\section{Carlos Costa}

Department of Economics, Management, Industrial Engineering and Tourism, Research Unit of Governance, Competitiveness and Public Policies (GOVCOPP), University of Aveiro, Portugal, ccosta@ua.pt

Received: 10.09.2021; Revisions required: 04.11.2021; Accepted: 14.01.2022

\begin{abstract}
The main aim of this paper is the analysis of the third sector arts, culture and local development organisations (TSO) participation in the context of tourism planning and development and to understand the characteristics of its connections to the tourism sector in the region of the Algarve. The methodological strategy is anchored in a mix-methods approach applying qualitative techniques such as semistructured interviews $(n=40)$, document analysis, non-participant observation, and adopting a triangulation approach. There have been few empirical studies that analyse this theme, thus, identifying the forms of participation that the third sector can adopt and their characteristics constitutes one of the main contributions of this research towards reinforcing the conceptual framework in the context of responsible tourism development. The results revealed that third sector organisations display a set of characteristics that position them as active agents in the tourist planning and development processes by operating on areas such as the promotion of cultural expression, research and inventory of cultural and natural resources, raising awareness of those resources and also by actively participating in supply structuring of tourist services.
\end{abstract}

Keywords: Tourism development, third sector organisations, arts and culture, local development, Algarve.
Resumo

O artigo tem como principal objetivo a análise das formas de participação que o terceiro setor com intervenção nos domínios das artes, cultura e do desenvolvimento local pode assumir no contexto dos processos de planeamento e desenvolvimento turístico, bem como compreender as caraterísticas das suas ligações ao setor turístico na região do Algarve. A metodologia adotada assenta numa abordagem de métodos mistos, tendo-se utilizado técnicas qualitativas, como a entrevista semiestruturada ( $n=40)$, a análise documental e a observação não participante, adotando o método da triangulação. São poucos os estudos empíricos que analisam esta temática, deste modo, a identificação das formas de participação que o terceiro sector pode assumir, as suas características e especificidades, constitui um dos contributos principais da investigação para o reforço do quadro conceptual no âmbito do desenvolvimento turístico responsável. Os resultados revelam que as organizações do terceiro setor apresentam caraterísticas que as posicionam como agentes ativos nos processos de planeamento e desenvolvimento turístico, ao operar em áreas tais como a promoção da expressão cultural e artística, a investigação e inventariação dos recursos culturais e naturais, aumentando o conhecimento sobre estes recursos e participando ativamente no apoio à estruturação de atividades turísticas.

Palavras-chave: Desenvolvimento turístico, organizações do terceiro sector, artes e cultura, desenvolvimento local, Algarve.

\section{Introduction}

In the 21st century, there is recognition of the strategic importance of a process of tourist planning and development in destinations, with the public sector, companies, third sector organisations (TSO) and residents of their respective territories all participating in these processes (UNEP \& UNWTO, 2005; Gunn \& Var, 2002). There is also consensus that tourism can have a positive effect on local economies, particularly due to its capacity to open up territories to visitors from other countries and regions and with the consequent effect of maximizing the value of endogenous resources.

Studying the participation of communities in the context of tourism is even more important as tourism is one of the world's main economic sectors. According to UNWTO (2020), there were 1,460 million international tourist arrivals in 2019 , which corresponds to an average annual growth of $4 \%$. Europe continued its position as the main tourist region, with 744 million international tourist arrivals in the same year, representing more than half the number of international tourists (51\%). Data concerning the sub-region of Southern Europe and the Mediterranean, which is the geographic location of Portugal and the Algarve - the tourist destination under study - show that it is among the leaders in international tourist arrivals regarding the European tourist region.

In the same year, Portugal moved up two places in the global ranking of international tourist arrivals. This placed it as the 15th most visited tourist destination in the world with a total of 24.6 million international tourists, corresponding to $7.9 \%$ growth compared to the previous year. Portugal gained market share in world terms, growing well above the world ( $+3.6 \%)$ and European $(+4.0 \%)$ averages, as well as the average for Southern Europe and the Mediterranean region ( $+5.4 \%$ ). Among the top 20 tourist destinations in the world, Portugal had the third-highest levels of growth in relative terms (Turismo de Portugal, 2020).

The Algarve is recognized as an important Portuguese tourist destination for both Portuguese and foreign tourists; it 
represents $34 \%$ of overnight stays in the country and makes a significant contribution to the national economy through the revenue generated (Turismo de Portugal, 2020). This region is bordered by the Atlantic Ocean and Spain, the second-largest tourism destination generator of revenue and international tourist arrivals worldwide. The Algarve must thus necessarily take on the challenge of asserting itself in a proposal for tourism development based on the specificities of its territory, with a tourism development model that is environmentally, culturally, socially and economically responsible.

The present moment can thus be seen as extremely important for the transition and affirmation stages of this model. This is the result of a set of circumstances, particularly the rise of disintermediation, which have caused profound changes in sectors such as accommodation and transport and which have affected the way the tourism system works. At its base, disintermediation represents both a challenge and an opportunity for host communities (Buhalis et al., 2019). Recently, as a result of the COVID-19 pandemic, seen from a tourist demand outlook, the following trends, among others, have been identified: travel to nearby places and an increase in domestic tourism; higher demand for nature activities and less mass-tourist destinations which aim to preserve nature and culture, although the demand for beach destinations remains; trips to secondary cities, contact with the resident community, willingness of visitors to actively support local production and commerce and to enhance the value of products and services that maximize the positive impact of tourism in the environmental, socio-cultural and economic dimensions. Lastly, the demand for destinations that protect and value local communities is expected to increase, with the tourist experience being seen as a way to generate direct benefits for the local economy and to preserve heritage (OECD, 2020).

Given these trends in the tourist demand, destinations' managing organisations should support and promote companies and local producers, create tourist experiences which imply an increase in average tourist spending and the deconcentration of tourist flows in these territories. The phenomena of tourism development and host communities are therefore two intrinsically related situations. The participation of communities in tourist development processes can therefore be seen as a requirement for putting sustainable tourism practices into operation.

Tourism is considered a pillar of community development and also, in a dialectical process, the participation of communities in tourism planning and development is seen as a requirement for sustainable tourist practices. Underlying these principles, it is also pertinent to emphasize that all actors involved in tourism development (local organisations, companies, tourism professionals, associations, non-governmental organisations, and also host communities and tourists) have different but interdependent responsibilities for the individual and social enhancement of tourism. This paper is written from this viewpoint, and the empirical study focuses on the ways in which communities participate via the third sector in the context of tourist activity. The main objective is to understand how the third sector, by means of its interventions in the field of arts, culture and local development, can play an active role in the context of processes of tourism planning and development.

\section{Literature review}

While climate, sun and sea will continue to determine tourist motivations to a large extent, it is generally agreed that tourist experiences are also associated with a search for places with an authentic and genuine character and their own distinct atmosphere (Urry, 1990). The participation of communities in these processes is thus of central importance and acts as an anchor by creating links to local economies (Inskeep, 1991; Moscardo, 2008; Murphy, 2014).

This assumption effectively means that decisions on the best way to leverage their resources - specific and non-transferable - should be taken within communities. It will thus be possible to overcome the limitations and negative impacts that occurred in the past in most second-generation resorts within the framework of the tourism development model of international tourism from the mid-1960s to the 1980 s along the Mediterranean region (Holloway \& Humphreys, 2020).

The tourism development model followed during this period was typified by undervaluation of community participation, with the literature providing clear evidence of the consequences. Notable among the main features of this model of (mass) tourism development are the geographic concentration of tourists in ecologically sensitive areas (coastlines) and a business model controlled by the tour operator, in a logic of all-inclusive services, (air transport, accommodation, meals, transfers). This generated temporary, low-skilled and low-paid employment, as well as the erosion of local investment in agriculture and small industries (e.g. fishing). Added to these aspects is the fact that most tour operators had their company headquarters in the tourists generating countries, which means that a large part of the revenue from tourist businesses remained in these countries of origin (Butler, 2011).

In this scenario, the role of the third sector is significant from the outset, due to the characteristics on which its decision-making model is based: democratic principles that guide its creation and existence, allowing broader participation in the definition of the development model itself, and also its proximity to the communities from which it emerges (CIRIEC, 2012).

These characteristics help recognize the third sector's potential to mobilize communities and initiate endogenous development processes, with repercussions for the local productive fabric and for creating and maintaining jobs. In the European context, despite the specificities of different countries, the third sector is associated with collective entrepreneurship and is seen as an emerging sector which is forging a new production model. It has an intermediate dimension, provides connection between 
sectors and has close connections to communities, with the capacity to create jobs that do not require relocation.

It can also be seen that the characteristics of these organisations tend, to a certain extent, to be the result of their democratic nature and the principles that guide their existence. Among these, the fact of being private, self-governing and having autonomy of management are notable, and this places them in an ideal position to actively intervene in the processes of sustainable tourism planning and development (CIRIEC, 2012; Murphy, 2014).

Among the above characteristics, some of which have already been identified by authors in the area of tourism, the attributes of the third sector allow it to adopt a role in terms of community empowerment, advocacy, service provision, social innovation (creation of new ideas and projects) and thus at the level of local and regional development. In addition to this, when exploring the specific dimensions of the cultural third sector, is its role in terms of individual and collective participation and the promotion of cultural and artistic expression in the fields of arts and culture, as well as its role in creating social capital that are highlighted by several authors (Andersson \& Getz, 2009).

In a similar vein, Gunn \& Var (2002) highlight the contribution of the third sector in the context of tourism development, particularly associations in the areas of culture, heritage and the environment, in that they carry out and manage services for visitors. The authors draw attention to the role that these organisations can play, in particular in terms of stimulating and supporting small-scale tourism projects. They thus also create a desirable balance with the presence of multinational companies, which also tend to establish themselves in destinations as soon they perceive opportunities to invest in tourism. Murhpy (2014, p. 121) also highlights this role: "Input from concerned community groups could provide a balance to the short-term objectives of the business sector, and possibly encourage greater variation and local flavour in future projects which would be a welcome change from the growing homogenization of present development."

This view of the involvement of the non-profit sector in tourism development processes is shared by authors such as Timothy (2007) and Tosun (1999); however, despite this recognition, it appears that studies on the connection between the area of tourism and third sector organisations are relatively scarce. Existing studies have focused on participation in the management of cultural attractions and organisation of events, volunteering and the role of non-governmental organisations in the context of environmental impacts and sustainability ((Andersson \& Getz, 2009; Parkinson, 2006, Simpson, 2008).

Many of the cultural events that take place in tourist destinations are organized by associations with links to the arts and culture, and in many situations, they play the role of guardians and promoters of local identity. It is precisely this genuine character, which contributes to places' atmosphere and determines it to a great extent, which some authors recognize as making an important and distinctive contribution to the visitor experience. Andersson \& Getz (2009:5) recognize the opportunity for cooperation, noting that the provision of services, in the field of cultural activities and events, can generate opportunities for the communities and for tourism: "In tourism, there may be a similar role for not-for-profit organisations to provide services to the community - services that also generate opportunities for the tourism industry (...) Not-for-Profit organisations involved in organising cultural activities may, therefore, receive a part of their financing form public sources and part in the form of business revenue. Therefore, not-for-profit organisations occupy a borderline area where they encroach on both public services and private commerce. They are in a position where they can cooperate with both sectors".

The literature enables us to identify a set of forms of participation associated with these organisations, which can be seen to provide added value and have a positive effect on tourism development. Notable among these are support for maintaining economic activities which are at risk of disappearing, for example handicrafts, and empowering and mobilizing communities to engage in pilot projects with potential tourism interest. When exploring the specific dimensions of the cultural third sector, it also has a role in terms of individual and collective participation and the promotion of cultural and artistic expression.

The concept of Responsible Tourism was proposed in the context of the Cape Town Declaration in 2002 (Fabricius, \& Goodwin (2020). Goodwin (2016) states that it is based on the idea that tourism should contribute to create better places for people to live in and better places for people to visit, requiring that all of the tourism stakeholders take responsibility and take steps to make tourism more sustainable. According to the Declaration, responsible tourism development aims to minimize negative social, economic and environmental impacts; generate direct economic benefits for local communities and improve their well-being; involve locals in decision making regarding tourism development; make positive contributions to the conservation of natural and cultural heritage; create authentic experiences for tourists through more meaningful connections with the local community; be culturally sensitive and build respect between hosts and guests and to provide access for physically challenged individuals Authors such as Leslie (2012) and Mihalic (2016) also claim that the notion of responsibility relates to responsible behaviour and action from the perspective of tourism stakeholders. In this paper, we argue that the reinforcement of cooperation initiatives between tourism organisations, companies and third sector organisations can be understood as an implementation of responsible tourism thinking into practice.

\section{The Algarve}

Located in the south of Portugal, the Algarve region occupies $6 \%$ of the country with a population of 440 thousand 
inhabitants. It has a characteristic temperate climate with Mediterranean influences. The region's diverse morphology means it is subdivided into three natural sub-regions (Figure 1): the Serra Algarvia (mountain area), which occupies about 50\% of the region's surface area and has low levels of agriculture, high rates of human desertification and ageing, poorly qualified population with low entrepreneurial capacity; the Barrocal Algarvio (hill area), which represents about $25 \%$ of the area of the region, with a high level of agriculture; and the Litoral
Algarvio (coastal area), where most of the region's economic activity in the area of services is concentrated, as well as the main urban centres. Services, with the main emphasis on tourism, are the defining activities in the Algarve economy. The Algarve region is undergoing demographic growth as it is sought out by people from different countries, either as a destination to which to emigrate or as a place in which to purchase a second home (CCDRAlg, 2020).

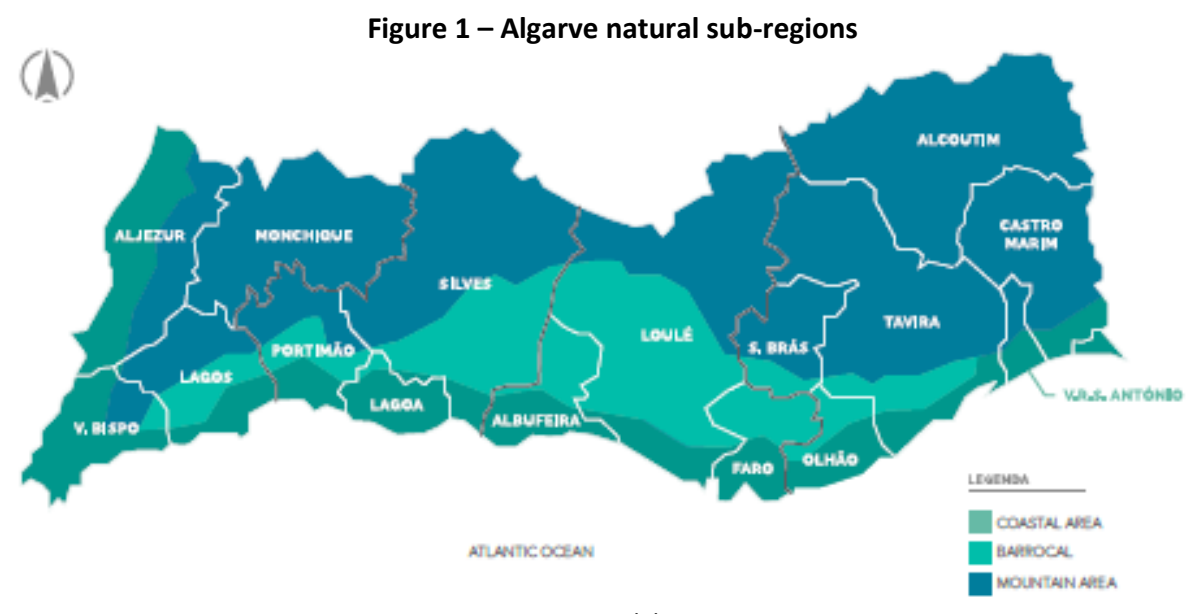

Source: Own elaboration.

Regarding tourism development, the coastal area is in a mature phase according to the tourism area life cycle model (Butler, 2011), while the Barrocal shows signs of tourist growth and is undergoing a development phase. The development level of tourism in the Serra is very low and this natural sub-region can be considered as being in an early stage of development. Signs of a phase of tourism development can be detected in these areas (Barrocal and Serra) and of their connections to the coast due to the initiatives that have been carried out, which are described in section 5.5.

This region is a prime area for tourism due to its natural conditions, namely its mild climate and beaches, which enabled sun and sea tourism to develop, especially after the construction of Faro International Airport in 1965.

As a destination, the Algarve has lived through the specific circumstances of second-generation resorts which are part of the history of international tourism in the Mediterranean regions. These include spontaneous and increasing tourist demand, real estate speculation, unplanned construction on the coastline, intensive exploitation of natural resources and dependence on a limited number of outbound markets. From a structural point of view, in recent decades, the Algarve has gone from an underdeveloped region, with an essentially agricultural economy and some industry resulting from land and sea resources, to a predominantly service-based region clustered around activities linked to tourism. The structural imbalance has intensified and the presence of agriculture and industry in the region is now scarce.
Faro International Airport is the main gateway for foreign tourists visiting the Algarve and connects the region to around sixty international airports; it is approximately a 2.5-hour flight from the main European capitals. In terms of incoming markets, the four with the highest volume of passengers are the United Kingdom (54\%), Germany (11\%), the Netherlands (9\%) and Ireland (8\%), which together represents approximately $82 \%$ of the total number of passengers processed. The Algarve represents $34 \%$ of total overnight stays (from domestic and foreign tourists) and is thus the leader in the domestic tourism scenario (Turismo de Portugal, 2020).

The regional tourism supply is divided into 17 products/segments with different levels of development. These reflect a focus on traditional products that are already well established and which have a high level of international recognition (sun and sea, golf and residential tourism) or emerging segments that are responsive to trends in the sector (nature tourism, gastronomy and wines, cultural tours), in a logic of year-round diversification and affirmation of the destination, thus reducing seasonality (CCDRAlg, 2020).

The Algarve, as a tourism destination, faces challenges such as the need to: increase the average length of stay of visitors and, consequently, their average expense; structure distinctive tourist experiences; deconcentrate tourist flows in the territory from the Litoral to the Barrocal and Serra and, consequently, allowing a more responsible and ethical distribution of the benefits of tourism and, ultimately, implementing tourism strategies centred on the economic, social, environmental and cultural sustainability of the region. 


\section{Methodology}

The reflection carried out in the literature review led to the definition of the problem under study, which is substantiated in the following research problem: What forms of participation can the third sector adopt within the context of the planning and development of tourist destinations?

Creswell (2009) argues that in situations where the phenomenon under study needs more in-depth analysis, due, for example, to the lack of prior empirical research, a qualitative approach tends to be more favourable. That was the approach adopted in this study, using semi-structured interviews with third sector leaders $(n=30)$ and key informants $(n=10)$, nonparticipant observation and document analysis as data collection techniques (Table 1). The research was based on the triangulation method, with the combined use of the three techniques (Quivy \& Campenhoudt, 1992).

Data collection took place between 2012 and 2020, which allowed the work developed by the organisations to be followed over a number of years and also made it possible to detect changes resulting from the initiatives and projects they carried out.

Table 1 - Data collection methods and techniques

\begin{tabular}{|l|l|}
\hline $\begin{array}{l}\text { Longitudinal non- } \\
\text { participant } \\
\text { observation }\end{array}$ & $\begin{array}{l}\text { Participation in events (seminars, } \\
\text { workshops, cultural events and other } \\
\text { occasions related to activities carried } \\
\text { out by the TSO in the Algarve region). }\end{array}$ \\
\hline $\begin{array}{l}\text { Semi-structured } \\
\text { exploratory interviews }\end{array}$ & $\begin{array}{l}\text { TSO leaders }(n=30) \\
\text { Key informants }(n=10)\end{array}$ \\
\hline Document collection & $\begin{array}{l}\text { TSO activity plans, organisations' } \\
\text { official sites, inventory of activities } \\
\text { and initiatives carried out by TSO. }\end{array}$ \\
\hline
\end{tabular}

Interviews were carried out in this group with thirty leaders of TSO in order to ascertain what forms of participation are employed by third sector organisations in the context of tourism development in established sun and sea destinations. Representatives of local development associations (LDA), culture and arts associations, non-governmental environmental organisations and foundations were included.

Ten interviews were also carried out with key informants (KI), individuals in the tourism sector with experience of working in third sector organisations. These have in-depth knowledge due to their actions and responsibilities of the topic under analysis; they have the ability to articulate this knowledge and their perspectives can contribute to an understanding of the research topic (Flick, 2009).

Regarding the decision of who to interview, the leaders of the respective organisations were established as the group of choice, for reasons related to the nature of the questions raised, which presuppose leadership and management experience in this area.
With regard to sampling, this study adopted an intentional, non-probabilistic sample, used in qualitative studies when the goal is to obtain a diversity of points of view (Patton, 2002; Yin, 2009). In the scope of intentional sampling techniques, the snowball technique was chosen. This has advantages in that the researcher is thus able to reach a group of people who are in the target recognition group by means of third parties, insofar as they have relevant experience and information within the scope of the subject under study. On the other hand, it also enables the researcher to identify the moment at which he/she has a sufficiently robust set of information that enables him/her to proceed to the phase of analysing the data collected, that is, to identify the moment when a "point of saturation" is reached. In this case, the principle of theoretical saturation or qualitative isomorphy is respected, which occurs when respondents no longer supply answers which are different from those that have already been obtained (Yin, 2009).

The final interview script includes twelve open-ended questions around four major themes: 1) areas of intervention and main challenges (this theme is only applicable to managers of third sector organisations); 2) connection to the tourism sector; 3 ) opportunities arising from their links to tourism; 4) forms of participation of third sector organisations in the context of tourism.

Given the qualitative nature of the information collected, content analysis was chosen as a data-processing technique. According to Vala (1986:111), content analysis is one of the most commonly used techniques in empirical research in the human and social sciences, as "based on an explicit logic, it allows inferences to be made about the messages whose features were inventoried and systematized".

In data treatment, the five sequential phases of the content analysis technique proposed by Creswell (2009) were followed: preparation and organisation; identification of the main categories for data analysis; coding of interviews; comparison of different cases; and interpretation of results and conclusions.

The process of identifying the main categories constitutes a crucial phase in qualitative analysis and determines the final results. According to Vala (1986), the construction of a system of categories can be done a priori or a posteriori, or through the combination of these two processes.

In some studies, a deductive method (a priori) is used in the first phase; this consists of the creation of categories suggested by a review of the literature on the subject under study. Then, in the second phase, it is complemented (a posteriori) with an inductive method, with categories being derived from the interviewees' discourse (Jennings, 2010). In this research, we opted for a system of creating categories using a combination of these two processes.

For each category created, quotations (registration units) from the interviews carried out are given to illustrate the respective category and, whenever justified, information and data arising 
from the non-participant observation and analysis of the documentation collected are also included.

\section{Main results and discussion}

\subsection{Main aims and scope of intervention of TSO in the Algarve}

The distribution of the TSO sample by main scope of intervention is presented in Table 2. The performing arts are most prevalent, with $43.3 \%$ of the TSO surveyed. Organisations that undertake activities in the areas of supporting and disseminating the region's gastronomy, wines and traditional products, and organisations which have activities in the promotion of arts and crafts, handicrafts and design are equally represented (16.7\%) and are the second most represented type of organisations in the sample. Organisations that intervene in local development and in environmental advocacy have a 13.3\% representation and associations that intervene in the areas of culture and heritage make up $10 \%$ of the TSO surveyed.

Table 2 - Distribution of the sample of TSO - Area of activity

\begin{tabular}{|l|c|}
\hline \multicolumn{1}{|c|}{ Main area of activity } & $\begin{array}{c}\text { Relative } \\
\text { frequency }\end{array}$ \\
\hline Local development and environment & $13.3 \%$ \\
\hline Arts and crafts, handicrafts and design & $16.7 \%$ \\
\hline Culture and heritage & $10.0 \%$ \\
\hline Gastronomy and wines inventory and promotion & $16.7 \%$ \\
\hline Performing arts & $43.3 \%$ \\
\hline Total & $\mathbf{1 0 0 \%}$ \\
\hline
\end{tabular}

Source: Own elaboration.

Within this diversity of organisations, there are different legal forms such as non-profit cultural associations, local development associations, non-governmental organisations (NGOs), foundations and cooperatives. It should be noted that $30 \%$ of TSO have a special status, which means they are recognized as Local Action Groups (LAG), in the case of Local Development Associations (LDA). When asked about the target audience of the activities carried out, a significant majority of respondents identified "residents and visitors of the region" as benefitting from their actions (76.7\%). For $13.3 \%$ of respondents, the activities undertaken are intended only for their members. Financing for TSO comes mainly from external sources, namely community funds (38.5\%), local authorities (29.5\%) and regional administration (13.6\%). The provision of services represents a small percentage at $8 \%$, followed by membership fees (4.5\%) and national administration (4.0\%). The main sources of funding for LDA are European Union funds, representing $71 \%$, followed by the provision of services with $10 \%$ of global funding. For associations linked to the arts and culture, the main source of funding is the local public sector, which represents $54 \%$ of global funding, followed by funding from regional bodies (19\%). In both cases, these organisations have a high level of dependence on external funding.

The empirical study provided an understanding of the motivations that guide the creation of TSO. Among the reasons mentioned by the interviewees, those centred on their connection to communities, encouragement of performing arts, the promotion and dissemination of cultural routes expressed through crafts, culture, gastronomy and heritage (table 3) are evident:

Table 3 - Aims for the TSO organisations creation

"The association's main aims are the advocacy, rehabilitation, rehabilitation and promotion of the natural and cultural heritage of the Algarve region". (TSO interviewer 4)

"From the outset, it is the association's intention to undertake efforts to identify, promote, create and disseminate cultural activities, and also to debate ideas and promote the Algarve region's culture". (TSO interviewer 5)

"Our mission is centred on the promotion and development of design and arts and crafts in the Algarve (...) it is our intention to establish a structure of mutual assistance and cooperation between associates, so that activities and projects which are of interest to all can emerge (...) and to encourage and promote creative areas and create opportunities in the region". (TSO interviewer 6 )

"The main goal of the association is to create themed spaces to promote the gastronomy and culture of the Algarve". (TSO interviewer 7)

"The main objectives are the training of musicians as well as participation in and promotion of artistic events". (TSO interviewer 8)

"We are an organisation of artistic theatrical production (...) in addition to artistic production, the association also operates in issues of training and audience awareness". (TSO interviewer 9)

"The association aims to promote cultural, artistic and social development through study and training activities, dissemination of knowledge in the fields of the arts, and by promoting transdisciplinary projects and organising events". (TSO interviewer 10)

"Our activity and reason for being are centred around the preservation, development and support of original handicraft and improving conditions for the creation and production of handicraft items or agri-food products, as long as they use raw materials and/or natural elements". (TSO interviewer 11)

"The promotion of cultural, recreational and environmental activities open to the community of municipalities in the Algarve in collaboration with other local entities, aiming at the human, social and cultural development of the populations concerned". (TSO interviewer 12)

"We are a service-based cooperative; we work in the areas of creating and organising events with an impact on the community, consultancy in the area of tourism, and supporting the undertaking of projects in rural areas". (TSO interviewer 14) 
The main goals that guided the creation of these organisations and that orient their activities enable a view of some of their forms of participation in the context of tourism planning and development processes identified in the literature review.

Regarding the main areas of intervention, it appears that their participation in events, whether from the perspective of responsibility for their creation and organisation, or at the invitation of public sector entities, constitutes a common area of intervention for the various types of organisations. Research in the areas of traditions, heritage, crafts and culture, the creation of itineraries associated with these dimensions, raising awareness and informal education are also common areas of action for the various associations.

The areas of intervention of the local development associations have some specific features, depending on their nature (Table 4).

Table 4 - Areas of intervention of the TSO

Participation and/or organisation of events (for example, Feira da Serra, Bird Watching Festival, Nature Tourism Biennial, craft fairs, gastronomy, among others).

Research in the areas of heritage, traditions, archaeology, environment, handicraft, among other aspects of local and regional culture.

Design and dissemination of itineraries and thematic routes (culture, gastronomy, nature and heritage).

Raising awareness and carrying out education and preservation of cultural and natural resources (organisation of workshops).

Source: Own elaboration.

The activities of TSO are thus in line with what is stated in the literature as concerns tourism trends, that is, the need for tourism to be developed based on the territories' unique cultural and natural characteristics (Inskeep, 1991; Murphy, 2014).

Regarding the cultural associations' areas of intervention, these appear to be focused on the communities' cultural development. Initiatives related to the performing arts, contemporary artistic creation and production in areas such as theatre, dance and music, among others are forms of individual and/or collective expression.

Analysis of the areas of intervention of TSO allows us to empirically ascertain the effective importance of their participation in tourism planning and development processes. It appears that these organisations operate in domains that directly contribute to the enhancement of the experience of visitors in the region, as advocated by authors such as Gunn \& Var (2002).

\subsection{Challenges for TSO in the Algarve}

The research allowed the identification of a set of challenges facing TSO in the Algarve region. Among the most frequently mentioned aspects in the interviewees' discourse was a concern with the issue of financial sustainability, which was referred to by most of the interviewed leaders. Thus, the need to diversify the funding sources can be found in almost all their discourses: "Financial sustainability (...) we live in a difficult time; things have changed in recent years, and we have to change too if we want to be competitive. For example, in services provision, third sector entities have to stop being dependent - they have to have diversified sources of funding and they have to start taking the role of service providers". (TSO interviewer 1 )

Funding is a central aspect of the concerns of the leaders of these organisations. According to the respondents, financial survival is the main challenge facing TSO in the short and medium-term. When asked about how to respond to this challenge, the answers are also unanimous, stating the need to diversify the sources of funding, above all, through the provision of services and the creation of partnerships.

Thus, it can be concluded that the challenges they face are several, although they are mostly centred on the issue of financial sustainability. However, the existing limitations in terms of human resources in particular, and in terms of volunteering and the need to improve external communication, as well as to make efforts towards networking also represent fundamental challenges for these associations, albeit mentioned less frequently. The dimensions identified recur in theoretical and empirical studies of features of the third sector and highlight the main weaknesses inherent to it (Montserrat Balas, 2008).

5.3 Perceptions of the opportunities arising from the participation of TSO in tourism planning and development in the Algarve

When asked about the importance of tourism in the context of their areas of intervention, the leaders of the local development associations agreed that tourism was important as an instrument for the territories where they operate.

There is equal agreement on evidence of their active involvement in designing complementary products (e.g. gastronomic, nature, rural and cultural tourism and itineraries creation) and in the position they take as a way to lend value to existing resources in these territories. The following excerpts illustrate how these leaders view tourism and demonstrate how central it is to their activities and strategies:

"Tourism is transversal to almost all the association's work (...) our path as an association is, in part, through the mission of tourism. We think of tourism as an asset for the economic and social dynamics that we aim to develop in the territory (...) not for tourism itself, but as a means to improve the quality of life of our community. Therefore, tourism is the basic instrument that we have to secure the population". (TSO interviewer 2) 
In the excerpts below, a common element that can be seen in the discourse is the understanding that tourism in their territories of intervention is not an alternative to the predominant model of tourism in the Algarve based on sun and sea, but is a complement to it, with an outlook of geographical expansion of the tourist supply and creation of added value within the tourist experience. These perceptions confirm the importance of this perspective in the planning and development of tourism and, once again, provide evidence of the awareness of the participation of communities in the construction of strategies based on territories' resources (Murphy, 2014; Vasquéz, 2007).

One of the aspects most frequently mentioned by the key informants was the notion of the connection between local development associations and their ability to recognize the specificities and needs of the respective territories in which they operate, as illustrated in the following statements: "The associations have knowledge of the territory, and play a very important role, in that they can promote specific local features". (KY interviewer 1)

"The associations have a deep knowledge and experience of the terrain. They know the characteristics of the places and communities, and this is what makes the difference; they are local agents who can help companies". (KY interviewer 2).

The TSO also recognizes the existence of opportunities in tourism that can also reflect and respond to the challenges faced by associations, in particular in terms of funding and external communication: "The opportunities for associations are above all an increase in the number of participants in events and, consequently, an increase in revenue. It is also an opportunity to increase the dissemination of activities". (TSO interviewer 8)

Thus, the possibility of making cultural production known to a wider audience consisting of visitors from different countries of origin is seen as an opportunity that can bring benefits provided by a multicultural audience. Opportunities for deconcentrating tourist flows in the territory are very clear in the discourse of the leaders of local development associations. Their activities focus mainly on geographic areas with low population density, particularly in the mountain area, and they see the possibility of capturing the demand of those whose primary destination is the coastal area as an opportunity for tourist development in their territories, as can be gathered from the analysis of the following discourses: "Tourists are still focused on the coast, but they can make forays into the interior to consume some of these offers; there are experiences that can only be lived in these territories and cannot be transported". (TSO interviewer 1)

It can thus be seen that the interviewees' opinions reflect a recognition regarding the proximity of the associations to local resources, meaning crafts, arts and local products. This proximity gives them the ability to play an active part in lending value to these resources.

\subsection{Forms of participation of TSO in tourism planning and development in the Algarve}

Regarding forms of participation of the TSO in the context of tourism development, the results reveal consensus on the importance and relevance of the participation of TSO in the scope of researching and inventorying cultural and natural resources. This is based on the perception of the characteristics associated with the third sector, namely the fact that the associations have close connections with the communities, which allows them to know the community's needs, as well as the existing resources.

There is broad recognition of the role of advocacy and the rising of awareness of resources among the key informants and TSO leaders. They clearly identify this as one of their areas of intervention and have a dynamic approach to enhancing these resources and of being open to the opportunities that tourism can bring.

Fostering cultural expression is adopted as an area of intervention by a considerable number of associations, particularly those operating within the scope of performing arts and culture.

Finally, it is worth noting the recognition by key informants and TSO leaders some examples of the participation of the third sector in supply structuring and provision of tourist services related to nature and rural tourism, routes and trails and in the participation of TSO in the launch of pilot initiatives. These are connected to tourism in the areas of environment, culture and heritage and in the promotion of endogenous resources, as can be seen in the two examples of cases of best practices in the following section (5.5).

Having presented the results from the interviews with the third sector leaders and key informants, it was considered pertinent to present examples of initiatives developed by two TSO in the Algarve region (Teia de Impulsos Association and QRER Cooperative for the Development of Low-Density Territories) that are worthy of attention. These are of particular interest for tourism, in terms of valuing natural heritage in inland territories and the gastronomic heritage of the region. They have direct and positive impacts on revitalizing its endogenous resources, deconcentrating tourist flows in the territory, increasing the average expenditure of visitors and reducing the seasonality associated with the sun and sea tourism product. They also foster a connection between tourist activities and the local economy and generate greater economic, social and cultural value for the region.

\subsection{Best practices in TSO link to tourism development}

The case of the Teia de Impulsos Association - Rota do Petisco (Snack Route)

The Rota do Petisco is a cultural and recreational project which has been promoted by the Teia D'Impulsos Association since 2011. It consists of a gastronomic itinerary, involving several 
restaurants in different geographical areas (Litoral, Barrocal and Serra). The main goals of the Rota do Petisco are promoting local restaurants and commerce and disseminating traditional Portuguese cuisine, as well as revitalizing localities that host the initiative through social and cultural entertainment and the enrichment of the region's tourist supply outside the high season. The project started in 2011 with the participation of one municipality, and by 2016, 14 of the 16 municipalities in the Algarve had already joined. Participants in the Rota do Petisco are invited to tour the various participating establishments guided by a passport which identifies all the stops on the route and the respective special menus prepared for the event. By 2020 , around 112,000 menus had been sold, with a direct economic impact of approximately 319,000 euros. At the root of the project is an aspect of solidarity - A Rota Solidária [Solidarity Route]. The amount of $€ 1.50$ paid for the passport reverts in full to support social projects developed by institutions in the locations participating in the event. Over the last six years, around 143,000 euros has been raised and more than 70 social projects supported. The Rota has managed to revive the concept of "snacking" in the region, as a synonym for stopping, taking a break from everyday life and socializing, in tune with the underlying motivations for the practice of slow tourism (Associação Teia de Impulsos, 2021).

\section{The case of QRER Cooperative - the Ameixial Walking Festival}

The Ameixial Walking Festival (AWF) has taken place in April every year since 2013 in the village of Ameixial, in the mountain area of Algarve. Its aim is to raise awareness of the cultural and natural value of the inland area, to raise awareness among communities of the value of the territory's resources; support the local economy; promote nature and cultural tourism, in particular, the practice of hiking; and contribute to the sustainable and balanced revitalization of the territory. The programme includes walks, workshops and lectures. The theme that the festival invokes - A Escrita do Sudoeste (Writing of the Southwest) - is unique and exclusive to the region. Writing of the Southwest is a form of communication in stone blocks that were fixed to the ground (stelae) found in the inland areas of the Algarve, that dates back to VI and V Century B.C.. The AWF is promoted by QRER Cooperative for the Development of LowDensity Territories (Cooperativa QRER, 2021).

This event made a direct contribution to the initiative subsequently supported by the Algarve Tourism Region, Algarve Walking Season, a regional project for the joint promotion of walking festivals in the Algarve in three different municipalities, two of which are located in the mountain area of the region (Serra Algarvia) and take place in the spring and one in the autumn, on the coast.

The Teia de Impulsos Association and QRER are examples of particular interest in that they are initiatives that emerged from the third sector and are responsible for the creation, implementation and coordination of projects that add value to both the community and to the tourism sector. Without their know-how and access to endogenous resources, it would have been difficult for the private tourism sector to set up initiatives of this nature.

\section{Conclusions}

Studies on tourism and development highlight how important it is for various stakeholders to participate in the processes of responsible and sustainable tourism and how this broadened participation can bring added value to communities. From this standpoint, the participation of third sector organisations can be more easily achieved, as these entities have a certain level of organisation. The results of the study lead us to the conclusion that there are points of convergence between the areas of intervention of TSO and the challenges facing tourism, both in terms of demand and supply. From this research, it can be concluded that there are: various areas in which these organisations intervene, carrying out activities that highlight the region's potential; a proactive stance regarding some associations in identifying and seeking solutions to existing structural problems in these territories; an active stance in stimulating the performing arts, promoting and adding value to the dimensions of culture, heritage and gastronomy; the consensus among the leaders of the TSO regarding the importance of tourism as an instrument for local and regional development; evidence of the involvement of these organisations in designing complementary products linked to nature, to geographically expand the tourist supply and create added value for the region.

As regards the opportunities which arise from the participation of TSO in the context of tourism in the Algarve, analysis of the interviewees' discourse demonstrates that, regardless of the type of interviewee, appreciation of local resources (crafts, culture, and gastronomy) emerges as the category of greatest consensus. This is in line with what is argued in the literature regarding the centrality of endogenous resources in strategies for tourism development, and the active role played by the third sector in this area should be acknowledged.

Regarding the forms of participation of the third sector in the context of tourism development, the research results reveal consensus on how important and pertinent it is for TSO to participate in researching and inventorying of cultural and natural resources. This perception is based on the characteristics associated with the third sector, particularly the fact that the associations have close connections to the local communities, which allows them to know both their needs and the characteristics of existing resources.

There is also evidence of the recognition by key informants and TSO leaders of the role of advocacy and raising awareness of resources and recognition by key informants and TSO leaders of the participation of the third sector with intervention in local development, in the design and supply services linked to nature and rural tourism, routes and trails. 
The empirical study allowed more in-depth knowledge to be gained in what concerns the areas of intervention of TSO and the challenges and perceptions regarding the opportunities arising from their participation in the context of tourism in the Algarve. More specifically, it enabled important contributions to be identified regarding the forms of participation that TSO can adopt in the context of tourism planning and development in the region. It was thus possible to ascertain, whether in the interviews or by means of observation or documental analysis, that the greatest consensus around forms of participation of the third sector in the tourist context lies in research and inventorying and raising awareness of resources. A position of active participation was perceived in valuing these resources and in terms of the opportunities that tourism can provide for them.

TSO have the potential to make their region distinctive. They may positively affect tourist development on a local level, and should therefore be understood as a natural ally of the public sector and of tourism companies. Through their active participation, it is possible to identify and value the critical success factors of places more accurately due to their proximity to the communities, which then leads to an easier and more beneficial acceptance and implementation of measures for developing responsible tourism initiatives. Fieldwork was carried out in the Algarve region; as a result, the particularities and uniqueness of the place must be taken into consideration. Given this limitation, findings presented in this paper qualify as a contribution to further develop and refine the research regarding the forms of participation that TSO can assume in tourism development, therefore, the results are not statistically representative, nor should one expect them to generalize across different cultural contexts, this way the paper should be seen as a step in the quest to understand how organized civil society can participate in tourism planning and development.

Acknowledgements: The authors are thankful for support from Centre for Tourism Research, Development and Innovation (CiTUR) [FCT - Foundation for Science and Technology through project ref. UIDB/04470/2020].

\section{References}

Andersson, T. \& Getz, D. (2009). Tourism as a mixed industry: differences between private, public and not-for-profit festivals. Tourism Management, 30(6), 847-856.

Associação Teia de Impulsos. (2021). Rota do Petisco. Retrieved from https://teiadimpulsos.pt/projectos/cultural/rota-do-petisco.

Buhalis, D., Harwood, T., Bogicevic, V., Viglia, G., Beldona, S. \& Hofacker, C. (2019). Technological disruptions in Services: lessons from tourism and hospitality. Journal of Service Management, 30(4), 484-506.

Butler, R. (2011). Tourism area life cycle. Contemporary tourism reviews. Oxford: Goodfellow Publishers Limited.

CCDRAlg. (2020). Algarve 2030 - Estratégia de Desenvolvimento Regional. Comissão de Coordenação e Desenvolvimento Regional do Algarve, July 2020.

CIRIEC (2012). The Social Economy in the European Union. European Economic and Social Committee. International Centre of Research and Information on the Public, Social and Cooperative Economy: Brussels.

Cooperativa QRER. (2021). Walking Festival Ameixial. Retrieved from https://wfameixial.qrer.pt.
Creswell, Y. (2009). Research design qualitative, quantitative and mixed methods approaches. Thousand Oaks: Sage Publications.

Fabricius, M. \& Goodwin, H. (2020). Responsible tourism destinations: The Cape Town Declaration. Retrieved from https://responsibletourismpartnership.org/cape-town-declaration-onresponsible-tourism/(accessed on May 2020).

Flick, U. (2009). An Introduction to Qualitative Research. 4th edition, London: Sage.

Goodwin, H. (2016). Responsible Tourism: Using Tourism for Sustainable Development. Oxford: Goodfellow Publishers.

Gunn, C. A. \& Var T. (2002). Tourism Planning: Basics, Concepts and Cases. New York: Routledge.

Holloway, C. \& Humphreys, C. (2020). The Business of Tourism. London: Sage Publications.

Inskeep, E. (1991). Tourism Planning - an Integrated and Sustainable Approach. New York: Van Nostrand-Reinhold.

Jennings, G. (2010). Tourism Research. Milton Australia: John Wiley \& Sons.

Leslie, D. (Ed.). (2012). Responsible tourism: Concepts, theory and practice. Walingford: Cab International.

Mihalic, T. (2016). Sustainable-responsible tourism discourse Towards 'responsustable' tourism. Journal of Cleaner Production, 111(B), 461-470.

Montserrat Balas, L. (2008). El reto de la comunicación en el tercer sector no lucrativo. Revista Española del Tercer Sector, 8, 17-37.

Moscardo, G. (2008). Building Community Capacity for Tourism Development. Wallingford: Cab International.

Murphy, P. E. (2014). Tourism: a Community Approach. London: Routledge.

OECD (2020). Mitigating the impact of COVID-19 on tourism and supporting recovery. OECD Tourism Papers, No. 2020/03. Paris: OECD Publishing.

Parkinson, L. (2006). Managing a small non-profit tourism organisation. In J. Beech \& S. Chadwick (Eds.), The Business of Tourism Management (pp. 179-197). Harlow: Financial Times Press Pearson Education.

Patton, M. Q. (2002). Qualitative Research \& Evaluation Methods. Thousand Oaks, CA: Sage.

Quivy, R. \& Campenhoudt, L. V. (1992). Manual de Investigação em Ciências Sociais. Lisboa: Gradiva.

Simpson, M. (2008). Community Benefit Tourism Initiatives - A conceptual oxymoron? Tourism Management, 29, 1-18.

Timothy, D. J. (2007). Empowerment and stakeholder participation in tourism destination communities. In A. Church; T. Coles (eds.), Tourism, power, and space (pp. 199-216). Abingdon: Routledge.

Tosun, C. (1999). Towards a typology of community participation in the tourism development process. International Journal of Tourism and Hospitality, 10(2), 113-134.

Turismo de Portugal (2020). Desempenho Turístico. Retrieved from https://business.turismodeportugal.pt/pt/Conhecer/Apresentacao/De sempenho_Turistico/Paginas/default.aspx.

UNEP/UNWTO (2005). Making tourism more sustainable. A guide for policymakers. United Nations Environment Programme, Division of Technology, Industry and Economics and World Tourism Organisation. Paris, Madrid: UNEP, WTO.

UNWTO (2020). World Tourism Barometer, Volume 18, Issue 6, https://doi.org/10.18111/wtobarometereng.

Urry, J. (1990). The Tourist Gaze. London: Sage.

Vala, J. (1986). A análise de Conteúdo. In A. Silva; Pinto, J., Metodologia das Ciências Sociais (pp.101-128). Porto: Edições Afrontamento.

Yin, R. K. (2009). Case study research: Design and methods. Thousand Oaks, CA: Sage. 